\title{
Additional risk factors for infection by multidrug-resistant pathogens in healthcare- associated infection: a large cohort study
}

Teresa Cardoso ${ }^{1 *}$, Orquídea Ribeiro ${ }^{2}$, Irene César Aragão ${ }^{1}$, Altamiro Costa-Pereira ${ }^{2}$ and António Eugénio Sarmento ${ }^{3}$

\begin{abstract}
Background: There is a lack of consensus regarding the definition of risk factors for healthcare-associated infection (HCAl). The purpose of this study was to identify additional risk factors for HCAl, which are not included in the current definition of HCAl, associated with infection by multidrug-resistant (MDR) pathogens, in all hospitalized infected patients from the community.

Methods: This 1-year prospective cohort study included all patients with infection admitted to a large, tertiary care, university hospital. Risk factors not included in the HCAl definition, and independently associated with MDR pathogen infection, namely MDR Gram-negative (MDR-GN) and ESKAPE microorganisms (vancomycin-resistant Enterococcus faecium, methicillin-resistant Staphylococcus aureus, extended-spectrum beta-lactamase-producing Escherichia coli and Klebsiella species, carbapenem-hydrolyzing Klebsiella pneumonia and MDR Acinetobacter baumannii, Pseudomonas aeruginosa, Enterobacter species), were identified by logistic regression among patients admitted from the community (either with community-acquired or HCAl).
\end{abstract}

Results: There were 1035 patients with infection, 718 from the community. Of these, 439 (61\%) had microbiologic documentation; 123 were MDR (28\%). Among MDR: 104 (85\%) had MDR-GN and 41 (33\%) had an ESKAPE infection. Independent risk factors associated with MDR and MDR-GN infection were: age (adjusted odds ratio $(\mathrm{OR})=1.7$ and $1.5, p=0.001$ and $p=0.009$, respectively), and hospitalization in the previous year (between 4 and 12 months previously) (adjusted $\mathrm{OR}=2.0$ and $1,7, p=0.008$ and $p=0.048$, respectively). Infection by pathogens from the ESKAPE group was independently associated with previous antibiotic therapy (adjusted $O R=7.2, p<0.001$ ) and a Karnofsky index $<70$ (adjusted $\mathrm{OR}=3.7, p=0.003$ ). Patients with infection by MDR, MDR-GN and pathogens from the ESKAPE group had significantly higher rates of inadequate antibiotic therapy than those without (46\% vs $7 \%$, $44 \%$ vs $10 \%, 61 \%$ vs $15 \%$, respectively, $p<0.001$ ).

Conclusions: This study suggests that the inclusion of additional risk factors in the current definition of HCAl for MDR pathogen infection, namely age $>60$ years, Karnofsky index $<70$, hospitalization in the previous year, and previous antibiotic therapy, may be clinically beneficial for early diagnosis, which may decrease the rate of inadequate antibiotic therapy among these patients.

Keywords: Healthcare-associated infections, Multidrug resistant pathogens infection, Multidrug resistant gram negatives infection, ESKAPE microorganisms' infection, Independent risk factors, Inadequate antibiotic therapy

\footnotetext{
* Correspondence: cardoso.tmc@gmail.com

'Unidade de Cuidados Intensivos Polivalente, Hospital Geral de Santo António, University of Porto, Largo Prof. Abel Salazar, 4099-001, Porto, Portugal

Full list of author information is available at the end of the article
}

\section{Biomed Central}

(c) 2012 Cardoso et al.; licensee BioMed Central Ltd. This is an Open Access article distributed under the terms of the Creative Commons Attribution License (http://creativecommons.org/licenses/by/2.0), which permits unrestricted use, distribution, and reproduction in any medium, provided the original work is properly cited. 


\section{Background}

Traditionally, infections have been classified as community or hospital-acquired, according to their place of acquisition, and this classification is still used to guide diagnosis and treatment of infections [1,2]. However, an increasing number of patients reside in nursing homes, the use of aggressive medical therapies (intravenous therapy, wound dressing) at home is more common, an increasing number of invasive therapies (hemodialysis, chemotherapy, radiotherapy) are performed in outpatient clinics, and there is a greater population of older patients, with more chronic diseases and frequent utilization of medical resources. This has led to the creation of a new group among the traditional classification of infections, termed "healthcare-associated infections" (HCAI).

In 2002, Deborah Friedman and colleagues [3] proposed a definition of HCAI including the above subgroups of patients, but despite being widely used in clinical studies [4-9], there is a lack of consensus regarding risk factors, and more recent studies have included additional risk factors such as an immunocompromised state, hospitalization in the previous year and prior antibiotic therapy $[5,10]$. Unfortunately, most of the studies performed using the HCAI classification have been restricted to respiratory infections $[4,5,8,10]$, bloodstream infections $[3,6,11]$ or a single pathogenic agent $[7,9,12]$, creating the need to widen the study of risk factors for infection by multidrug-resistant (MDR) pathogens to all infected patients hospitalized from the community.

The objective of this study was to identify additional risk factors associated with infection by MDR pathogens in all infected patients admitted from the community into the hospital setting (patients with communityacquired and HCAI, including all foci of infection and associated pathogens), and not included in the adopted definition of HCAI [3].

\section{Methods}

\section{Study design and patient population}

A prospective cohort study was conducted in a 600-bed tertiary care university hospital, over a 1-year period (1 June 2008 to 31 May 2009). All consecutive adult infected patients admitted to the medical, surgical, nephrology or hematology wards of the hospital, or to the intensive care unit (ICU) were included, based on a diagnosis of infection according to the Center for Disease Control (CDC) criteria [1]. The primary outcome of interest was infection by a MDR pathogen. All patients completed the follow-up until hospital discharge. This study was approved by the Institutional Review Board of Hospital de Santo António, Oporto Hospital Centre,
Portugal, and informed consent was waived owing to the observational nature of the study.

\section{Definitions}

Community-acquired infection (CAI) was defined as an infection detected within $48 \mathrm{~h}$ of hospital admission in patients who did not fit the criteria for a HCAI.

HCAI was defined using the same criteria of Friedman et al. [3]-an infection present at the time of hospital admission or within $48 \mathrm{~h}$ of admission in patients that fulfilled any of the following criteria:

- received intravenous therapy at home; received wound care or specialized nursing care through a healthcare agency, family or friends; or selfadministered intravenous medical therapy in the 30day period before the onset of the infection;

- attended a hospital or hemodialysis clinic, or received intravenous chemotherapy in the previous 30 days;

- hospitalized in an acute care hospital for 2 or more days in the previous 90 days;

- resided in a nursing home or long-term care facility.

Hospital-acquired infection (HAI) was defined as a localized or systemic condition that resulted from an adverse reaction to the presence of an infectious agent(s) or its toxin(s), and that occurred $48 \mathrm{~h}$ or more after hospital admission and was not incubating at the time of admission [1]. Infections in patients recently discharged from hospital within the previous 2 -week period were also included in this group.

The CDC definitions were used to define infections at different anatomic sites [1]. The definition of MDR organisms used was adopted from the CDC recommendations for the management of MDR organisms in healthcare settings that defines MDR organisms as bacteria that are resistant to one or more classes of antimicrobial agents recommended as first line therapy [13]. Thus, enteric Gram-negative rods were considered MDR (MDR-GN) if they were resistant to amoxicillin-clavulanate, piperacillintazobactam, carbapenems, aztreonam, fluoroquinolones, or third-generation cephalosporins or aminoglycosides. Acinetobacter spp. and Pseudomonas spp. were considered MDR if they were resistant to piperacillin-tazobactam, imipenem/meropenem, aztreonam, ciprofloxacin, cefepime, ceftazidime, aminoglycosides or colistin.

We grouped vancomycin-resistant Enterococcus faecium, methicillin-resistant Staphylococcus aureus (MRSA), extended-spectrum beta-lactamase (ESBL)-producing Escherichia coli and Klebsiella species, carbapenemhydrolyzing Klebsiella pneumonia and MDR Acinetobacter baumannii, Pseudomonas aeruginosa and Enterobacter species into a group denominated ESKAPE, according to 
a previous publication of the Infectious Diseases Society of America [14].

The presence of ESBL production among E. coli and Klebsiella spp. strains was screened by the automatic analyzer Vitek2 (bioMérieux, France). It was confirmed by a disk diffusion test that detects synergism between the cephalosporins/monobactam and clavulanate. If the interpretation of the results was doubtful, we also performed the Etest ${ }^{\circledR}$ (AB Biodisk, Solna, Sweden); a combination of cefotaxime and cefotaxime/clavulanate and ceftazidime and ceftazidime/clavulanate indicated ESBL production whenever the ESBL ratio with antibiotic:antibiotic+inhibitor was $\geq 8$.

The presence of carbapenemase production in Enterobacteriaceae was suspected whenever minimum inhibitory concentrations for ertapenem, imipenem and meropenem exceeded $0.5,1$ and $1 \mu \mathrm{g} / \mathrm{mL}$, respectively. In such cases, a modified Hodge test was performed, and the ultimate confirmatory test was carbapenemase detection by molecular methods.

The risk factors studied for association with infection by MDR pathogens (including MDR-GN and the ESKAPE group) included age, sex, previous antibiotic therapy (in the last month prior to the current infection), previous hospitalization (in the last 12 months prior to the current infection, but not in the last 3 months), patient comorbidities and general medical condition. The comorbidities studied included immunosuppression (administration of radiation therapy in the 12 months prior to hospital admission, administration of $0.2 \mathrm{mg} / \mathrm{kg} /$ day of prednisolone for at least 3 months prior to hospital admission, administration of $1 \mathrm{mg} / \mathrm{kg} /$ day of prednisolone for 1 week in the 3 months prior to hospital admission or infection with human immunodeficiency virus), chronic liver disease [15], chronic heart failure [15], chronic respiratory disease [15], hematological disease [16], cancer (metastatic disease not under chemotherapy in the previous 12 months), diabetes mellitus requiring insulin therapy or oral hypoglycemic agents before the infection and/or atherosclerosis (defined as a previous history of a transient ischemic attack, stroke, angina, myocardial infarction or peripheral arterial disease). The patient's general medical condition was assessed by the Karnofsky index [17]. A score of lower than 70 implies that the patient is unable to perform normal activities or do active work.

Adequacy of initial antibiotic therapy, hospital length of stay, Simplified Acute Physiology Score (SAPS II) and hospital mortality were also compared between groups of patients with and without infection by MDR pathogens (MDR-GN and ESKAPE). The initial empirical antibiotic treatment was considered "adequate" if the response to the initial antibiotic prescribed within $24 \mathrm{~h}$ of diagnosis matched in vitro susceptibility of the pathogen deemed to be the likely cause of the infection, and when the dosage and route of administration were appropriate for the patient's current medical status (focus and severity of infection); only patients with positive microbiology were considered in this analysis. SAPS II [16] was recorded on the first day of antibiotic therapy.

\section{Statistical analysis}

Continuous variables are described as mean and standard deviation (SD), or as median and inter-quartile range if they showed a skewed distribution. Categorical variables are described with absolute frequencies and percentages. Comparison of demographic and clinical characteristics of infected patients from the community (either with CAI or HCAI) and patients with HAI was made using the Student $t$-test (for continuous variables with normal distribution), the Mann-Whitney $U$ test (for continuous variables with skewed distribution) and the Pearson $\chi^{2}$ test (for categorical variables).

Comparison of inadequate antibiotic therapy, hospital length of stay, SAPS II and hospital mortality between the group of patients infected with MDR pathogens and those not infected, along with comparison of the group infected by MDR-GN with those not infected, and the group infected by ESKAPE pathogens and those not infected, was made with the same tests according to the type of variables compared (continuous with normal distribution, continuous with skewed distribution or categorical).

All variables potentially associated with MDR pathogen infection (including MDR-GN and ESKAPE pathogens) were studied among all infected patients admitted from the community, those with CAI and HCAI, and included: age, sex, previous antibiotic therapy, hospitalization in the previous year, immunosuppression, chronic hepatic disease, chronic heart failure, chronic respiratory disease, chronic hematologic disease, cancer, diabetes, atherosclerosis and decreased functional capacity (Karnofsky index $<70)$. Those with a clear association in the univariate analysis $(p<0.1)$ were included in the multivariable analysis. The results of the multivariable models are expressed as odds ratio (OR) with $95 \%$ confidence interval and $p$ values. The calibration was tested using the HosmerLemeshow goodness-of-fit test. The significance level was defined as $p<0.05$. Data were analyzed using SPSS version 18 for Windows (SPSS Inc., Chicago, IL, USA).

\section{Results}

During the study period a total of 3733 patients were assessed and 1035 (28\%) met the inclusion criteria of having infection according to the CDC definitions of infection. The mean \pm SD age of the patients included was $65 \pm 20$ years, and the mean SAPS II was $29 \pm 13$; $49 \%$ of patients were male, and the overall hospital mortality rate was $13 \%$ (Table 1). Of these, 718 were admitted to hospital from the community with infection: 493 (48\%) with a CAI and 225 
Table 1 Demographic and clinical characteristics of patients, according to place of acquisition of infection

\begin{tabular}{|c|c|c|c|c|}
\hline Patients' characteristics & TOTAL $(n=1035)$ & CAI and HCAI $(n=718)$ & HAI $(n=317)$ & $p$-value \\
\hline Male sex, n (\%) & $506(49)$ & $344(48)$ & $162(51)$ & $0.343^{*}$ \\
\hline Age, mean (SD) & $65(20)$ & $65(20)$ & $64(19)$ & $0.405^{\&}$ \\
\hline SAPSIII, mean (SD) & $29(13)$ & $29(12)$ & $30(13)$ & $0.962^{\&}$ \\
\hline Severity of infection, n (\%) & & & & $0.922^{*}$ \\
\hline Localized infection without SIRS & $281(27)$ & $195(27)$ & $86(27)$ & \\
\hline Sepsis & $364(35)$ & $251(35)$ & $113(36)$ & \\
\hline Severe sepsis & $296(29)$ & $209(29)$ & $87(27)$ & \\
\hline Septic shock & $94(9)$ & $63(9)$ & $31(10)$ & \\
\hline Previous comorbidities, n (\%) & $671(65)$ & $460(64)$ & $211(67)$ & $0.438^{*}$ \\
\hline Chronic hepatic disease, n (\%) & $22(2)$ & $18(3)$ & $4(1)$ & $0.822^{\$}$ \\
\hline Chronic renal disease, n (\%) & $149(14)$ & $94(13)$ & $55(17)$ & $0.072^{*}$ \\
\hline Chronic heart failure, n (\%) & $74(7)$ & $46(6)$ & $28(9)$ & $0.163^{*}$ \\
\hline Chronic respiratory disease, n (\%) & $66(6)$ & $52(7)$ & $14(4)$ & $0.086^{*}$ \\
\hline Hematologic disease, n (\%) & $60(6)$ & $35(5)$ & $25(8)$ & $0.056^{*}$ \\
\hline Cancer, n (\%) & $45(4)$ & $26(4)$ & $19(6)$ & $0.084^{*}$ \\
\hline Diabetes, n (\%) & $204(20)$ & $144(20)$ & $60(19)$ & $0.674^{*}$ \\
\hline Atherosclerotic disease, n (\%) & $242(23)$ & $168(23)$ & $74(23)$ & $0.985^{*}$ \\
\hline Immunosuppression, n (\%) & $221(21)$ & $137(19)$ & $84(27)$ & $0.007^{*}$ \\
\hline Karnofsky index<70, n (\%) & $319(31)$ & $227(32)$ & $92(29)$ & $0.405^{*}$ \\
\hline Hospitalization in the previous year, n (\%) & $413(40)$ & $239(33)$ & $174(55)$ & $<0.001^{*}$ \\
\hline Previous antibiotic therapy, n (\%) & $367(36)$ & $137(19)$ & $230(73)$ & $<0.001^{*}$ \\
\hline Hospital mortality, n (\%) & $138(13)$ & $79(11)$ & $59(19)$ & $0.001^{*}$ \\
\hline
\end{tabular}

CAI - community-acquired infection, HCAI - healthcare-associated infection, HAI - hospital-acquired infection, IQR - Inter-quartile range, SD - Standard deviation, SOFA - Sepsis-related Organ Failure Assessment, SIRS - Systemic inflammatory response syndrome.

*Pearson Qui-square Test; ${ }^{\$}$ Fisher exact test; \& Independent samples $t$-test.

(22\%) with a HCAI. These populations were significantly different from patients with HAI, with a lower proportion of immunosuppressed patients (19\% vs 27\%, $p=0.007$ ), a lower proportion of hospitalizations in the previous year (33\% vs 55\%, $p<0.001$ ) and less likelihood of antibiotic therapy in the last month $(19 \%$ vs $73 \%, p<0.001)$. Hospital mortality was significantly lower in patients from the community (CAI or HCAI) than in those with HAI (11\% vs $19 \%, p<0.001$ ) (Table 1). Of the 718 patients with CAI or HCAI, 439 (61\%) had microbiologic documentation; of these, 123 were MDR (28\%), 104 (85\%) with MDR-GN and 41 (33\%) with ESKAPE organisms.

From the univariate analysis, age, previous antibiotic therapy, hospitalization in the previous year (from 4 months to 1 year), chronic heart failure, chronic respiratory disease, atherosclerosis and a Karnofsky index $<70$ were selected for multivariate analysis of independent risk factors associated with infection by MDR pathogens, including infection by MDR-GN (Table 2). For the ESKAPE group, previous antibiotic therapy, hospitalization in the previous year, and a Karnofsky index $<70$ were the variables selected for the multivariate model (Table 2).

Regarding infection by MDR pathogens, the final model retained age (adjusted OR per category $=1.7, p=0.001$ ) and hospitalization in the previous year (from 4 months to 1 year) (adjusted $\mathrm{OR}=2.0, p=0.008$ ) (Table 3 ) as independent risk factors. The final model for MDR-GN infection also retained age (adjusted OR per category $=1.5, p=0.009$ ) and hospitalization in the previous year (from 4 months to 1 year) (adjusted $\mathrm{OR}=1.7, p=0.048$ ) (Table 3 ). For ESKAPE pathogen infection, the final model retained previous antibiotic therapy (adjusted OR $=7.2, p<0.001$ ) and Karnofsky index $<70$ (adjusted OR $=3.7, p=0.003$ ) (Table 3).

Patients with infection by a pathogen belonging to one of the three MDR groups had a significantly higher rate of inadequate antibiotic therapy: $16 \%$ in the study population, $46 \%$ in the group of patients with infection by MDR pathogen, $44 \%$ in the group with infection by MDR-GN, and $61 \%$ in the group with an ESKAPE group infection $(p<0.001)$. Despite that, median hospital length of stay was similar in all groups, as were SAPS II and hospital mortality rate (Table 4).

\section{Discussion}

In this study, age $>60$ years, hospitalization in the previous year (in the last 4 to12 months), previous antibiotic therapy (last month) and Karnofsky index $<70$ were 
Table 2 Risk factors for MDR, MDR gram-negatives and ESKAPE group pathogens infection

\begin{tabular}{|c|c|c|c|c|c|c|c|c|c|c|c|}
\hline Variables & $\begin{array}{l}\text { Total, } n(\%) \\
\mathrm{n}=718\end{array}$ & $\begin{array}{l}\text { Microbiological } \\
\text { documentation, } n \text { (\%) } n=439\end{array}$ & $\begin{array}{l}\text { MDR, } n(\%) \\
n=123\end{array}$ & $\begin{array}{l}\text { Crude } \\
\text { OR }\end{array}$ & $\begin{array}{l}\mathrm{p}- \\
\text { value }\end{array}$ & $\begin{array}{l}\text { MDR-GN, n (\%) } \\
n=104\end{array}$ & $\begin{array}{l}\text { Crude } \\
\text { OR }\end{array}$ & $\begin{array}{l}\mathrm{p}- \\
\text { value }\end{array}$ & $\begin{array}{l}\text { ESKAPE pathogens, } \\
n(\%) n=41\end{array}$ & $\begin{array}{l}\text { Crude } \\
\text { OR }\end{array}$ & $\begin{array}{l}\mathrm{p}- \\
\text { value }\end{array}$ \\
\hline Age & & & & $1.6^{*}$ & $<0.001$ & & $1.5^{*}$ & 0.009 & & $1.3^{*}$ & 0.170 \\
\hline$\leq 60$ years & $271(38)$ & $166(38)$ & $33(27)$ & & & $30(28)$ & & & $13(32)$ & & \\
\hline $61-80$ years & $250(35)$ & $157(36)$ & $44(36)$ & & & $37(36)$ & & & $13(32)$ & & \\
\hline$>80$ years & $197(27)$ & $116(26)$ & $46(37)$ & & & $37(36)$ & & & $15(36)$ & & \\
\hline Male sex & 344 (48) & 203 (46) & $56(46)$ & 1.1 & 0.656 & $45(43)$ & 0.9 & 0.542 & $21(51)$ & 1.2 & 0.503 \\
\hline Previous antibiotic therapy & $137(19)$ & $94(21)$ & $38(31)$ & 1.9 & 0.009 & $30(29)$ & 1.7 & 0.033 & $20(49)$ & 4.2 & $<0.001$ \\
\hline $\begin{array}{l}\text { Hospitalization in the previous year } \\
\text { ( } 4 \text { months }-1 \text { year) }\end{array}$ & $146(20)$ & $102(23)$ & $37(30)$ & 2.1 & 0.006 & $29(28)$ & 1.8 & 0.031 & $14(34)$ & 3.3 & 0.003 \\
\hline $\begin{array}{l}\text { Immunosupression (not meeting } \\
\text { criteria of HCAl) }\end{array}$ & $113(16)$ & $81(19)$ & $25(20)$ & 1.1 & 0.685 & $24(23)$ & 1.5 & 0.116 & $10(24)$ & 1.5 & 0.306 \\
\hline Chronic hepatic disease & $18(3)$ & 14(3) & $4(3)$ & 0.9 & 0.818 & $3(3)$ & 0.9 & 0.829 & $2(5)$ & 1.7 & 0.522 \\
\hline Chronic heart failure & $46(6)$ & $27(6)$ & $13(11)$ & 2.5 & 0.026 & $11(11)$ & 2.3 & 0.038 & $2(5)$ & 0.8 & 0.723 \\
\hline Chronic respiratory disease & $52(7)$ & $30(7)$ & $13(11)$ & 2.2 & 0.056 & $11(11)$ & 1.9 & 0.093 & $4(10)$ & 1.6 & 0.439 \\
\hline Chronic haematologic disease & $35(5)$ & $29(7)$ & $8(7)$ & 1.0 & 0.945 & $5(5)$ & 0.7 & 0.444 & $5(12)$ & 2.2 & 0.139 \\
\hline Cancer (not meeting criteria of HCAl) & $10(1)$ & $6(1)$ & $2(2)$ & 1.5 & 0.666 & $2(2)$ & 1.6 & 0.578 & $0(0)$ & & \\
\hline Diabetes & $144(20)$ & $96(22)$ & $32(26)$ & 1.3 & 0.291 & $27(26)$ & 1.4 & 0.239 & $11(27)$ & 1.4 & 0.421 \\
\hline Atherosclerosis & $168(23)$ & $105(24)$ & $40(33)$ & 1.8 & 0.017 & $32(31)$ & 1.6 & 0.069 & $13(32)$ & 1.5 & 0.222 \\
\hline Karnofsky index<70 & $227(32)$ & $149(34)$ & $57(46)$ & 1.8 & 0.006 & $44(42)$ & 1.6 & 0.046 & $22(54)$ & 2.5 & 0.006 \\
\hline
\end{tabular}

Association of demographic and clinical variables with infection by MDR, MDR gram negatives and ESKAPE pathogens among patients admitted from the community (with community-acquired or healthcare-

associated infections), using logistic regression.

*insociated infections), using logistic regression.

- multi-drug resistant; MDR-GN - multi-drug resistant gram negatives; OR - odds ratio; ESKAPE - Vancomycin-resistant Enterococcus faecium, MRSA, ESBL producing E.

coli and Klebsiella species, Klebsiella pneumonia Carbapenamase-hydrolyzing and MDR Acinectobacter baumannii, Pseudomonas aeruginosa and Enterobacter species. 
Table 3 Independent variables associated with infection by MDR, MDR gram-negatives and pathogens from the ESKAPE group

\begin{tabular}{|c|c|c|c|c|c|c|c|c|c|c|c|c|}
\hline Variables & $\begin{array}{l}\text { MDR, } \\
n(\%) \\
n=123\end{array}$ & Adjusted OR & $\mathrm{Cl}_{95 \%}$ & p-value & $\begin{array}{l}\text { MDR Gram } \\
\text { negatives, } \\
n(\%) n=104\end{array}$ & Adjusted OR & $\mathrm{Cl}_{95 \%}$ & p-value & $\begin{array}{l}\text { ESKAPE } \\
\text { pathogens, } \\
n(\%) n=41\end{array}$ & Adjusted OR & $\mathrm{Cl}_{95 \%}$ & p-value \\
\hline Age & & 1.7 & $1.3-2.3$ & 0.001 & & 1.5 & $1.1-2.1$ & 0.009 & & & & \\
\hline$\leq 60$ years & $33(27)$ & & & & $30(28)$ & & & & $13(32)$ & & & \\
\hline $61-80$ years & $44(36)$ & & & & $37(36)$ & & & & $13(32)$ & & & \\
\hline$>80$ years & $46(37)$ & & & & $37(36)$ & & & & $15(36)$ & & & \\
\hline Previous antibiotic therapy & $38(31)$ & & & & $30(29)$ & & & & $20(49)$ & 7.2 & $3.1-17.0$ & $<0.001$ \\
\hline Hospitalization in the previous year ( 4 months - 1 year) & $37(30)$ & 2.0 & $1.2-3.4$ & 0.008 & $29(28)$ & 1.7 & $1.0-3.0$ & 0.048 & $14(34)$ & & & \\
\hline Karnofsky index<70 & $57(46)$ & & & & $44(42)$ & & & & $22(54)$ & 3.7 & $1.6-8.6$ & 0.003 \\
\hline
\end{tabular}

Selection of variables significantly and independently associated with infection by a MDR pathogen, MDR gram negative or a pathogen from the ESKAPE group, among the group of patients admitted from the community (with community or healthcare-associated infection), using multiple logistic regression.

*increase in the odds per category of age; MDR - multi-drug resistant; OR - odds ratio; CI - confidence interval; ESKAPE - Vancomycin-resistant Enterococcus faecium, MRSA, ESBL producing E. coli and Klebsiella species, Klebsiella pneumonia Carbapenamase-hydrolyzing and MDR Acinectobacter baumannii, Pseudomonas aeruginosa and Enterobacter species. 
found to be significantly and independently associated with infection by MDR pathogens. These risk factors were not considered in the definition of risk factors of HCAI proposed by Friedman et al. Patients with infection by MDR microorganisms had a significantly higher rate of inadequate initial antibiotic therapy, but did not have a longer hospital length of stay or higher hospital mortality rate. This is probably one of the first studies containing a thorough description of independent and significant risk factors associated with infection by pathogens of the ESKAPE group as well as their impact regarding inadequate antibiotic therapy, hospital length of stay and hospital mortality.

In order to define the new group of infections across community and hospital settings, a definition of all risk factors for MDR pathogen infections is required. The definition proposed by Friedman et al. [3] is one of the most used in clinical studies regarding HCAI, but it was developed for bloodstream infections. Further studies followed, using similar definitions, but again only for a single focus of infection or single pathogens. Our study identified additional risk factors for MDR pathogen infection.

Micek et al. [10] performed a retrospective cohort study of hospitalized patients with pneumonia, and identified immunocompromised state and hospitalization in the previous 12 months as risk factors for HCAI. They found a higher proportion of MDR organisms in the HCAI group, with a significant association with inappropriate antibiotic therapy and hospital mortality rate. One limitation discussed by the authors was the fact that they did not evaluate severity-of-illness scores. In the current study severity scores were considered and they were similar in all groups, with no significant differences in hospital mortality rate between groups. Park et al. [5] also performed a retrospective cohort study on HCAIpneumonia, using the Friedman et al. definition and prior antibiotic therapy in the 30 days before the pneumonia episode, and found a higher proportion of MDR pathogens when compared with community-acquired pneumonia, and a significant association with inappropriate initial antibiotic therapy. Brito and Niederman [18] performed a review of all articles published since the American Thoracic Society guidelines were published [2], and concluded that patients at risk of pneumonia by MDR pathogens were those who had severe illness, were hospitalized in the past 90 days, had antibiotic therapy in the past 6 months, had poor functional status as defined by activities of daily living score, and were immunosuppressed, similar to the risk factors described here.

Wright et al. [19] performed a retrospective cohort study to determine risk factors for MDR pathogens among patients in the Emergency Department with urinary tract infections, and described the following independent risk factors: age $\geq 65$ years, diabetes, prior use of antibiotics, and urinary catheterization. Chen et al. [20] studied patients from the community with bacteremia but with prior hospitalization from periods of 3-90, 91-180 to up to 181-360 days, and concluded that the presence of antimicrobial-resistant bacteria in the past 360 days was an independent risk factor for antimicrobial-resistant bacteremia, reaffirming that hospitalization in the previous year represented a risk factor for MDR pathogen infection. Pop-Vicas et al. [21], in a 6-year study of patients with positive cultures for MDR organisms, noted an increasing prevalence of MDR-GN at admission to a tertiary-care hospital (positive cultures within the first $48 \mathrm{~h}$ after hospital admission). Factors independently associated with isolation of the resistant organisms were age $\geq 65$ years, prior antibiotic therapy for $\geq 14$ days and prior residence in a long-term-care facility.

The current study has the major advantage of being prospective, with clear and consensual definition of infection [1]. It included all major foci of infection that drove patients into hospital care and not only pneumonia, bacteremia or urinary infection as in other previous studies. It clearly identified the place of acquisition and the appropriateness of initial antibiotic therapy. Data regarding severity of illness and the impact of infection by MDR organisms in the appropriateness of initial antibiotic therapy, hospital length of stay and mortality rate were also investigated. Data collection was performed by a single trained doctor, and all protocols were completed with no missing data thus minimizing information bias. All patients completed follow-up until hospital discharge. Most importantly, risk factors described in this study have been previously mentioned in studies restricted to single focus of infection or pathogen, by other authors from different parts of the world, suggesting important external applicability of these conclusions.

The study also has certain limitations that should be acknowledged. The research was performed in a single institution and the number of patients from the community was relatively small. There is accumulating evidence that HCAI seems to be a group encompassing CAI and HAI, but specific definition of risk factors are lacking. The diversity of definitions used has led to diverse findings not comparable between studies, and therefore not consequential for specific treatment recommendations.

Implementation of standardized approaches for the treatment of HCAI is desirable, since failure to recognize this group of infected patients appears to be associated with administration of inappropriate antibiotic therapy in hospitalized patients with serious infection, and may be related to poor prognosis. 
Table 4 Impact of infection by MDR pathogens, including MDR gram-negatives and pathogens from the ESKAPE group, in antibiotic therapy and hospital outcome

\begin{tabular}{|c|c|c|c|c|c|c|c|c|c|}
\hline \multirow[t]{2}{*}{ Variables } & \multirow{2}{*}{$\begin{array}{l}\text { MDR, } \\
\text { n (\%) }\end{array}$} & \multirow{2}{*}{$\begin{array}{l}\text { Non- } \\
\text { MDR, } \\
\text { n (\%) }\end{array}$} & \multirow{2}{*}{$\begin{array}{l}\text { Non- MDR vs } \\
\text { MDR, } \\
\mathrm{p} \text { Value }\end{array}$} & \multirow{2}{*}{$\begin{array}{l}\text { MDR-GN } \\
\mathrm{n}(\%)\end{array}$} & \multirow{2}{*}{$\begin{array}{l}\text { Non-MDR- } \\
\text { GN, } \\
\mathrm{n}(\%)\end{array}$} & \multirow{2}{*}{$\begin{array}{l}\text { Non-MDR-GN vs MDR- } \\
\text { GN, } \\
p \text { Value }\end{array}$} & \multirow{2}{*}{$\begin{array}{l}\text { ESKAPE } \\
\text { pathogens, } \\
\mathrm{n}(\%)\end{array}$} & \multirow{2}{*}{$\begin{array}{l}\text { Non-ESKAPE } \\
\text { pathogens, } \\
\mathrm{n}(\%)\end{array}$} & \multirow{2}{*}{$\begin{array}{l}\text { Non-ESKAPE vs } \\
\text { ESKAPE, } \\
\mathrm{p} \text { value }\end{array}$} \\
\hline & & & & & & & & & \\
\hline Inadequate ATB therapy & $57(46)$ & $19(7)$ & $<0.001^{*}$ & $46(44)$ & $30(10)$ & $<0.001^{*}$ & $25(61)$ & $51(15)$ & $<0.001^{*}$ \\
\hline $\begin{array}{l}\text { Hospital LOS, median } \\
\text { (IQR) }\end{array}$ & $10(7-17)$ & $10(7-16)$ & $0.944^{\#}$ & $10(7-15)$ & $10(7-17)$ & $0.487^{\#}$ & $11(8-15)$ & $10(7-17)$ & $0.280^{\#}$ \\
\hline SAPS II, mean (SD) & $32(13)$ & $30(13)$ & $0.171^{\&}$ & $31(13)$ & $30(13)$ & $0.428^{\&}$ & $32(17)$ & $30(12)$ & $0.373^{\&}$ \\
\hline Hospital mortality & $19(15)$ & $31(12)$ & $0.280^{*}$ & $13(13)$ & $37(13)$ & $0.928^{*}$ & $9(22)$ & $41(12)$ & $0.062^{*}$ \\
\hline
\end{tabular}

Comparison of inadequate antibiotic therapy, hospital length of stay, SAPS II and hospital mortality between the group of patients infected with MDR pathogens and those not infected, along with comparison of the group infected by MDR-GN with those not infected, and the group infected by ESKAPE pathogens and those not infected.

ATB - antibiotherapy, CAI - community-acquired infection, LOS - length of stay, IQR - inter-quartil range, MDR - multi-drug resistant, MDR GN - multi-drug resistant gram negatives, ESKAPE - Vancomycin-resistant Enterococcus faecium, MRSA, ESBL producing E. coli and Klebsiella species, Klebsiella pneumonia Carbapenamase-hydrolyzing and MDR Acinectobacter baumannii, Pseudomonas aeruginosa and Enterobacter species.

*Pearson Qui-square Test; \# Mann-Whitney test, \&Students t-test. 


\section{Conclusions}

The results of this study suggest that the inclusion of additional risk factors for MDR pathogen infection in HCAI definition, namely age $>60$ years, Karnofsky index $<70$, hospitalization in the previous year, and previous antibiotic therapy, may be clinically beneficial because of early diagnosis and a decrease in the rate of inadequate antibiotic therapy in these patients. Further research involving a large number of patients from different institutions and geographic areas is warranted to confirm these findings.

\begin{abstract}
Abbreviations
CAl: Community-acquired infection; HCAl: Healthcare-associated infection; HAl: Hospital-acquired infection; MDR: Multidrug-resistant; MDRGN: Multidrug-resistant Gram-negative; ESKAPE: Vancomycin-resistant Enterococcus faecium, methicillin-resistant Staphylococcus aureus (MRSA), extended-spectrum beta-lactamase (ESBL)-producing E. coli and Klebsiella species, carbapenem-hydrolyzing Klebsiella pneumonia and MDR Acinetobacter baumannii, Pseudomonas aeruginosa and Enterobacter species; CDC: Center for Disease Control; ICU: Intensive Care Unit; MRSA: Methicillinresistant Staphylococcus aureus; ESBL: Extended-spectrum beta-lactamase; MIC: Minimum inhibitory concentration; SAPS: Simplified acute physiological score; IQR: Inter-quartile range; SD: Standard deviation; OR: Odds ratio; $\mathrm{Cl}_{\text {95\%: }}$ 95\% confidence interval.
\end{abstract}

\section{Competing interests}

The authors declare that they have no competing interests.

\section{Authors' contributions}

TC, ACP and AS conceived the study. TC coordinated data collection. TC and OR performed the statistical analysis. All authors participated in the analysis and interpretation of the data, clinical revision of the manuscript and final approval of the version to be published.

\section{Acknowledgments}

We are indebted to Dr. Luís Azevedo for the critical reading of the manuscript.

Supported by an unrestricted grant from ASSUCIP - Associação de Apoio à Unidade de Cuidados Intensivos Polivalente, Hospital de Santo António, Porto, Portugal (Intensive Care Unit Support Association).

Teresa Cardoso is partially funded by a PhD research grant from the Teaching and Research Department (Departamento de Formação, Ensino e Investigação) of Oporto Hospital Centre.

\section{Author details}

${ }^{1}$ Unidade de Cuidados Intensivos Polivalente, Hospital Geral de Santo António, University of Porto, Largo Prof. Abel Salazar, 4099-001, Porto, Portugal. '2Department of Health Information and Decision Sciences, Center for Research in Health Technologies and Information Systems (CINTESIS), Faculty of Medicine, University of Porto, Alameda Prof. Hernâni Monteiro, 4200-319, Porto, Portugal. ${ }^{3}$ Department of Infectious Diseases, Hospital de São João, University of Porto, Alameda Prof. Hernâni Monteiro, 4200-319, Porto, Portugal.

Received: 15 August 2012 Accepted: 13 December 2012 Published: 26 December 2012

\section{References}

1. Garner JS, Jarvis WR, Emori TG, Horan TC, Hughes JM: CDC definitions for nosocomial infections. Am J Infect Control 1988, 16:128-140.

2. American Thoracic Society: Guidelines for the management of adults with hospital-acquired, ventilator-associated, and healthcare-associated pneumonia. Am J Respir Crit Care Med 2005, 171(4):388-416.

3. Friedman ND, Kaye KS, Stout JE, McGarry SA, Trivette SL, Briggs JP, Lamm W, Clark C, MacFarquhar J, Walton AL, Reller LB, Sexton DJ: Health care-associated bloodstream infections in adults: a reason to change the accepted definition of community-acquired infections. Ann Intern Med 2002, 137(10):791-797.

4. Catarralà J, Mykietiuk A, Fernández-Sabé N, Suárez C, Dorca J, Verdaguer R, Manresa F, Gudiol F: Health care-associated pneumonia requiring hospital admission. Arch Intern Med 2007, 167(13):1393-1399.

5. Park HK, Song JU, Um SW, Koh WJ, Suh GY, Chung MP, Kim H, Kwon OJ, Jeon K: Clinical characteristics of health care-associated pneumonia in a Korean teaching hospital. Respir Med 2010, 104(11):1729-1735.

6. Vallés J, Calbo E, Anoro E, Fontanals D, Xercavins M, Espejo E, Serrate G, Freixas N, Morera M, Font B, Bella F, Segura F, Garau J: Bloodstream infection in adults: importance of healthcare-associated infections. $J$ Infect 2007, 56:27-34

7. Cheong HS, Kang C, Kwon KT, Heo ST, Wi YM, Kim ES, Lee JS, Ko KS, Chung DR, Lee NY, Song JH, Peck KR: Clinical significance of healthcareassociated infections in community-onset Escherichia coli bacteraemia. $J$ Antimicrob Chemother 2007, 60:1355-1360.

8. Rello J, Luján M, Gallego M, Vallés J, Belmonte Y, Fontanals D, Diaz E, Lisboa $T$, and for the PROCORNEU Study Group: Why mortality is increased in health-care-associated pneumonia: lessons from Pneumococcal Bacteremic Pneumonia. Chest 2010, 137:1138-1144.

9. Stryjewski ME, Kanafani ZA, Chu VH, Pappas PA, Harding T, Drew LA, Benjamin DK, Reller LB, Lee BA, Corey GR, Fowler VG: Staphylococcus aureus bacteremia among patients with health care-associated fever. Am J Med 2009, 122:281-289.

10. Micek ST, Kollef KE, Reichley RM, Roubinian N, Kollef MH: Health careassociated pneumonia and community-acquired pneumonia: a singlecenter experience. Antimicrob Agents Chemother 2007, 51(10):3568-3573.

11. Shorr AF, Tabak YP, Killian AD, Gupta V, Liu LZ, Kollef MH: Healthcareassociated bloodstream infection: a distinct entity? Insights from a large US database. Crit Care Med 2006, 34(10):2588-2595.

12. Tambyah PA, Habib AG, Toon-Mae N, Goh H, Kumarasinghe G: Communityacquired methicillin-resistant Staphylococcus aureus infection in Singapore is usually "Healthcare associated". Infect Control Hosp Epidemiol 2003, 24:436-438.

13. Siegel JD, Rhinehart $E$, Jackson $M$, Chiarello $L$, the healthcare Infection Control Practices Avisory Committee: Management of Multidrug-Resistant Organisms in Healthcare Settings, 2006. Atlanta, GA: Centers for Disease Control and Prevention (CDC); 2006:74.

14. Boucher HW, Talbot GH, Bradley JS, Edwards JE, Gilbert D, Rice LB, Scheld M, Spellberg B, Bartlett J: Bad bugs, no drugs: no ESKAPE! an update from the infectious diseases society of America. Clin Infect Dis 2009, 48(1):1-12.

15. Knaus WA, Draper EA, Wagner DP, Zimmerman JE: APACHE II: a severity of disease classification system. Crit Care Med 1985, 13(10):818-829.

16. Le Gall JR, Lemeshow S, Saulnier F: A new simplified acute physiology score (SAPS II) based on a European/North American multicenter study. JAMA 1993, 270(24):2957-2963.

17. Karnofsky DA, Burchenal JH: The Clinical Evaluation of Chemotherapeutic Agents in Cancer. In Evaluation of Chemotherapeutic Agents. Edited by MacLeod CM. Columbia: Univ Press; 1949:196.

18. Brito V, Niederman MS: Healthcare-associated pneumonia is a heterogeneous disease, and all patients do not need the same broad-spectrum antibiotic therapy as complex nosocomial pneumonia. Curr Opin Infect Dis 2009, 22(3):316-325.

19. Wright SW, Wrenn KD, Haynes M, Haas DW: Prevalence and risk factors for multidrug resistant uropathogens in ED patients. Am J Emerg Med 2000 18(2):143-146.

20. Chen SY, Wu GH, Chang SC, Hsueh PR, Chiang WC, Lee CC, Ma MH, Hung CC, Chen YC, Su CP, Tsai KC, Chen TH, Chen SC, Chen WJ: Bacteremia in previously hospitalized patients: prolonged effect from previous hospitalization and risk factors for antimicrobial-resistant bacterial infections. Ann Emerg Med 2008, 51(5):639-646.

21. Pop-Vicas AE, D'Agata EMC: The rising influx of multidrug-resistant gramnegative bacilli into a tertiary care hospital. Clin Infect Dis 2005, 40:1792-1798.

doi:10.1186/1471-2334-12-375

Cite this article as: Cardoso et al.: Additional risk factors for infection by multidrug-resistant pathogens in healthcare-associated infection: a large cohort study. BMC Infectious Diseases 2012 12:375. 